\title{
Is recurrence possible in coronavirus disease 2019 (COVID-19)? Case series and systematic review of literature
}

\author{
Anna Gidari ${ }^{1}$ (D) $\cdot$ Marco Nofri $^{1}$ (D) $\cdot$ Luca Saccarelli $^{2} \cdot$ Sabrina Bastianelli ${ }^{1} \cdot$ Samuele Sabbatini $^{3}$ (D) $\cdot$ Silvia Bozza $^{3}$ (D) \\ Barbara Camilloni ${ }^{3}$ (D) Igino Fusco-Moffa ${ }^{4}$ (D) Claudia Monari $^{3}$ (D) Edoardo De Robertis $^{2}$ (D) Antonella Mencacci $^{3}$ (D) \\ Daniela Francisci ${ }^{1}$ (1)
}

Received: 24 July 2020 / Accepted: 30 September 2020 / Published online: 10 October 2020

(C) The Author(s) 2020

\begin{abstract}
Can a patient diagnosed with severe acute respiratory syndrome coronavirus-2 (SARS-CoV-2) be infected again? This question is still unsolved. We tried to analyze local and literature cases with a positive respiratory swab after recovery. We collected data from symptomatic patients diagnosed with SARS-CoV-2 infection in the Italian Umbria Region that, after recovery, were again positive for SARS-CoV-2 in respiratory tract specimens. Samples were also assessed for infectivity in vitro. A systematic review of similar cases reported in the literature was performed. The study population was composed of 9 patients during a 4-month study period. Among the new positive samples, six were inoculated in Vero-E6 cells and showed no growth and negative molecular test in culture supernatants. All patients were positive for IgG against SARS-CoV-2 nucleoprotein and/or S protein. Conducting a review of the literature, 1350 similar cases have been found. The presumptive reactivation occurred in 34.5 days on average (standard deviation, SD, 18.7 days) after COVID-19 onset, when the 5.6\% of patients presented fever and the $27.6 \%$ symptoms. The outcome was favorable in $96.7 \%$ of patients, while the $1.1 \%$ of them were still hospitalized at the time of data collection and the $2.1 \%$ died. Several hypotheses have been formulated to explain new positive respiratory samples after confirmed negativity. According to this study, the phenomenon seems to be due to the prolonged detection of SARS-CoV-2 RNA traces in respiratory samples of recovered patients. The failure of the virus to replicate in vitro suggests its inability to replicate in vivo.
\end{abstract}

Keywords COVID-19 $\cdot$ SARS-CoV-2 $\cdot$ Recurrence $\cdot$ Reactivation $\cdot$ Re-infection

Anna Gidari and Marco Nofri contributed equally to this work.

Anna Gidari

anna.gidari@studenti.unipg.it

1 Department of Medicine, Clinic of Infectious Diseases, "Santa Maria della Misericordia" Hospital, University of Perugia, Perugia, Italy

2 Department of Anesthesiology, Intensive Care and Pain therapy Center, "Santa Maria della Misericordia" Hospital, University of Perugia, Perugia, Italy

3 Department of Medicine, Medical Microbiology Section, University of Perugia, Perugia, Italy

4 Department of Prevention, Local Health Unit Umbria 1, Travel Medicine Unit, Perugia, Italy

\section{Introduction}

Severe acute respiratory syndrome coronavirus-2 (SARSCoV-2) is the etiologic agent of coronavirus disease 2019 (COVID-19) that has been declared a global pandemic by the World Health Organization (WHO) in March 2020. SARS-CoV-2 was discovered in December 2019, in Wuhan City (the capital of Hubei province), China [1].

The origin of the virus remains unknown. However, newly diagnosed cases were initially linked to the Huanan Seafood Wholesale Market where people can buy animals that are butchered in loco. The virus was identified as a novel enveloped RNA beta-coronavirus that has been named SARS-CoV-2 [2].

As of September 2020, the total worldwide confirmed cases are 30,949,804 [3].

Albeit our knowledge of this virus has improved, it is still a challenging matter whether patients with SARS-CoV-2 
infection will reactivate the illness, and which risk factors predict eventual recurrence. Unraveling this topic is important to better understand the immune response to the virus and contain disease transmission.

After a prolonged scientific debate, the characteristics of a patient that can be discharged from the hospital have been standardized, in particular, improvement of symptoms (normal temperature lasting longer than 3 days and no more respiratory symptoms) and two negative swabs collected at least $24 \mathrm{~h}$ apart [4]. However, from June 17, WHO simplified criteria for discharge: for symptomatic patients, 10 days after symptom onset, plus at least 3 additional days, without symptoms (including no fever and respiratory symptoms) is enough to discharge patients from isolation [4].

However, several authors observed that in some cases patients presented a new positive respiratory sample after discharge. It is not clear yet what this means in terms of clinical course and contagiousness.

Here, we report the clinical and virologic findings of nine patients with a positive swab that had the criteria for discharge, in the Italian Umbria Region, from March to September. We also systematically revised all the similar cases reported in the literature so far, evaluating the possibility that COVID-19 may recur after recovery.

\section{Materials and methods}

\section{Patients, molecular tests, and in vitro viral infectivity}

Criteria for patients' selection were diagnosis of SARS-CoV2 infection [5]; the subsequent meeting of criteria for hospital discharge (improvement of symptoms and two negative swabs collected at least $24 \mathrm{~h}$ apart) [4]; and a positive respiratory sample collected after discharge.

All subjects provided informed oral consent to clinical data collection. The study was approved by the Ethics Committee of the Umbria Region (protocol number 18344/20/OV). Respiratory samples (nasopharyngeal swabs, sputum, tracheal aspirate, or bronchoalveolar lavage, BAL, fluid) were tested for SARS-CoV-2 RNA by a commercial reverse transcriptase real-time PCR assay (RT-PCR assay, Allplex ${ }^{\mathrm{TM}}$ 2019-nCoV Assay, Seegene, Seoul) and/or with the Xpert ${ }^{\circledR}$ Xpress SARS-CoV-2 (Cepheid, Sunnyvale, CA, USA). In particular, Allplex ${ }^{\mathrm{TM}}$ 2019-nCoV Assay was performed according to the manufacturer's instructions, using $300 \mu \mathrm{L}$ of respiratory samples and $10 \mu \mathrm{L}$ of the provided internal control (IC). The envelope $(E)$ gene (specific of the subgenus Sarbecovirus), the nucleocapsid gene $(N)$, and the RNA-dependent-RNApolymerase $(R d R P)$ genes (both specifics of the SARS-CoV2 ) were the targeted genes of the RT-PCR. The assay was considered valid if the cycle threshold $(\mathrm{Ct})$ value of the IC was $\leq 40$. Samples with 2 or 3 viral targets $(\mathrm{Ct} \leq 40)$ were considered positive. Samples with only 1 target (whatever $\mathrm{Ct}$ ) or with 2 or 3 targeted genes $>40 \mathrm{Ct}$ were considered indeterminate, requiring a new specimen for retesting. Samples were considered negative in the absence of any targeted gene. The fully automated Xpert Xpress ${ }^{\circledR}$ SARSCoV-2 assay was performed on the GeneXpert ${ }^{\circledR}$ platform (Cepheid) according to the manufacturer's instructions, loading $300 \mu \mathrm{L}$ of the sample into a single-use disposable cartridge. Targets were $\mathrm{E}$ and $\mathrm{N} 2$ genes. After results were automatically passed, they were interpreted as positive if both $\mathrm{E}$ and $\mathrm{N} 2$ targets were detected. If a gene alone was detected, the sample was considered indeterminate, and a new sample was retested.

The virus isolation was conducted in a biosafety level-3 facility. Samples tested positive for the SARS-CoV-2 in real-time RT-PCR analyses were mixed with a 1:1 nystatin $(10,000 \mathrm{U} / \mathrm{mL})$ and penicillin-streptomycin $(10,000 \mathrm{U} / \mathrm{mL})$ mixture in a $1: 4$ ratio, and left to react at $4{ }^{\circ} \mathrm{C}$ for $1 \mathrm{~h}$. The samples were then centrifuged at $400 \times \mathrm{g}$ for $10 \mathrm{~min}$, and the supernatant was used as the inoculant. For the cell inoculation, Vero E6 (ATCC® -1586) were maintained in Eagle's minimum essential medium (MEM) supplemented with $10 \%$ fetal bovine serum, and $1 \%$ penicillin-streptomycin at $37^{\circ} \mathrm{C}$ in the presence of $5 \% \mathrm{CO}_{2}$. On the day prior to inoculation, the cells were seeded at $0.5 \times 10^{4}$ cells $/ \mathrm{cm}^{2}$ into a T25 flask. The inoculated cells were cultured for 5 days as above described. To evaluate the viral replication process, the cytopathic effect was observed at different exposure times, and RNA from the cell culture supernatant was extracted and assessed for the presence of SARS-CoV-2 using real-time RT-PCR [6, 7]. The titer of IgG against the SARS-CoV-2 S1/S2 subunit of spike protein was measured with CLIA LIAISON® SARS-CoV-2 S1/ S2 IgG (DiaSorin).

\section{Systematic review}

Following the Preferred Reporting Items for Systematic Reviews and Meta-Analyses (PRISMA) Statement protocol [8], a systematic review has been performed concerning the patients with a diagnosis of COVID-19 that, after clinical and virological recovery, presented a new positive respiratory sample (swab, sputum, saliva, tracheal aspirate, or BAL).

A systematic search on PubMed and Google Scholar was performed from January to September 1, 2020. We used the following searching strategy: every search included the terms "SARS-CoV-2" or "COVID-19" and "reactivation" or "recurrence" or "relapse." Furthermore, we performed the following research: "(COVID-19 or SARS-CoV-2) and positive and (recovered or discharged)." Each article was analyzed to establish eligibility criteria and pertinency to our research. The inclusion criteria were as follows: English, Italian, or Spanish languages; pertinence on the question; articles that reported sufficient patients' information such as age, sex, 
and clinical and radiological presentation; treatment; and outcome.

The exclusion criteria were as follows: different languages from those mentioned above and abstract and posters from conference proceedings since they did not go through peer review.

Data were summarized using descriptive analysis where possible. We included our presented cases in the analysis. Statistical analysis was performed with Prism GraphPad 8 software. The figure was created using Microsoft PowerPoint 2020.

\section{Results}

\section{Study population}

From March to September 1, 2020, 9 patients meeting the inclusion criteria were included in the study. Patient characteristics and laboratory findings are summarized in Table 1.

\section{Case 1}

A 50-year-old man with a previous diagnosis of HBV infection developed fever on February 23, 2020, and cough on February 29, 2020. He was hospitalized on March 5, after being diagnosed with SARS-CoV-2 infection with a nasopharyngeal swab (Allplex ${ }^{\text {TM }}$ 2019-nCoV Assay).

On admission, he presented a severe respiratory failure. Although antiviral and antimicrobial therapies were started, blood gas exchanges rapidly worsened, and he was intubated and transferred to the intensive care unit (ICU), where he remained for 33 days.

The clinical course in ICU was complicated with two episodes of ventilator-associated pneumonia (VAP) and a central venous catheter (CVC)-related bloodstream infection due to a carbapenem-resistant Klebsiella pneumoniae.

Two consecutive endotracheal samples resulted negative for SARS-CoV-2 on March 16 and March 19. He underwent further endotracheal samples (March 23, April 6, and April 8), two of which came indeterminate and the other two negatives (Allplex ${ }^{\mathrm{TM}}$ 2019-nCoV Assay).

Between April 2 and April 8, qualitative serological tests (SCREEN@ TEST COVID-19, ScreenItalia) resulted positive for both IgG and IgM. A nasopharyngeal swab on April 9 tested positive. Another sample collected on April 13 resulted negative while another one collected on April 14 was positive (nasopharyngeal swab; Xpert ${ }^{\circledR}$ Xpress SARS-CoV-2, Cepheid). On April 23 and 24, two additional nasopharyngeal swabs tested negative again (Fig. 1a).

His SARS-CoV-2 serology, collected on May 8, was compatible with a previous infection (IgG $64 \mathrm{AU} / \mathrm{mL}$, LIASON® SARS-CoV-2 S1/S2 IgG, DIASORIN). As the clinical

Table 1 Severity of symptoms, laboratory exams, serology for severe acute respiratory syndrome coronavirus 2 (SARS-CoV-2), and SARS-CoV-2 culture at the first admission (where available) and at the presumptive recurrence of coronavirus disease 2019 (COVID-19)

\begin{tabular}{|c|c|c|c|c|c|c|c|c|c|c|c|}
\hline & \multicolumn{2}{|l|}{ Case 1} & \multirow{2}{*}{$\begin{array}{l}\text { Case } 2 \\
\text { New } \\
\text { positive }\end{array}$} & \multirow{2}{*}{$\begin{array}{l}\text { Case } 3 \\
\text { New } \\
\text { positive }\end{array}$} & \multirow{2}{*}{$\begin{array}{l}\text { Case } 4 \\
\text { New } \\
\text { positive }\end{array}$} & \multirow{2}{*}{$\begin{array}{l}\text { Case } 5 \\
\text { New } \\
\text { positive }\end{array}$} & \multirow{2}{*}{$\begin{array}{l}\text { Case } 6 \\
\text { New } \\
\text { positive }\end{array}$} & \multirow{2}{*}{$\begin{array}{l}\text { Case } 7 \\
\text { New } \\
\text { positive }\end{array}$} & \multicolumn{2}{|l|}{ Case 8} & \multirow{2}{*}{$\begin{array}{l}\text { Case } 9 \\
\text { New } \\
\text { positive }\end{array}$} \\
\hline & Admission & $\begin{array}{l}\text { New } \\
\text { positive }\end{array}$ & & & & & & & Admission & $\begin{array}{l}\text { New } \\
\text { positive }\end{array}$ & \\
\hline Symptoms & +++ & + & + & + & - & + & - & - & + & + & - \\
\hline $\mathrm{WBC}(/ \mathrm{mmc})$ & 6430 & 9180 & 6280 & 10,250 & 4430 & NA & 8390 & 3440 & 7630 & 7150 & 3010 \\
\hline Lymphocytes (/mmc) & 643 & 2552 & 1827 & 1158 & 1520 & NA & 3532 & 949 & 1381 & 2538 & 779.6 \\
\hline Neutrophils (/mmc) & 5497 & 5333 & 3768 & 8887 & 2340 & NA & 4279 & 2208 & 5691 & 4082 & 1911.4 \\
\hline CRP (mg/dL) & 5.7 & 1.3 & 0.3 & 0.3 & 0 & NA & 0.1 & NA & 7.7 & 0.1 & 0.3 \\
\hline PCT (ng/mL) & 0.28 & NA & 0.13 & $<0.12$ & NA & NA & $<0.12$ & NA & 0.39 & $<0.12$ & NA \\
\hline Creatinine $(\mathrm{mg} / \mathrm{dL})$ & 0.7 & 0.5 & 0.9 & 0.66 & 0.98 & NA & 0.98 & 0.94 & 0.68 & 0.61 & 1.05 \\
\hline AST (UI/L) & 76 & 26 & 24 & 17 & 37 & NA & 19 & 19 & 28 & 22 & 36 \\
\hline ALT (UI/L) & 62 & 62 & 33 & 17 & 39 & NA & 18 & 12 & 47 & 25 & 21 \\
\hline CPK (UI/L) & 618 & 28 & 92 & 65 & NA & NA & 38 & NA & 42 & 210 & 23 \\
\hline LDH (UI/L) & 518 & 244 & 190 & 186 & 171 & NA & 165 & 154 & 188 & 237 & 154 \\
\hline D-Dimer (ng/mL) & NA & 1350 & 340 & 558 & NA & NA & 242 & NA & NA & 166 & NA \\
\hline $\mathrm{IgG}$ anti-S1-S2 AU/ml & NA & 64.5 & 102 & 23 & 52.9 & 32.3 & NA & 18.7 & NA & 170.0 & 199.0 \\
\hline Virus culture & NA & Negative & NA & NA & NA & Negative & Negative & Negative & NA & Negative & Negative \\
\hline
\end{tabular}

Abbreviations: $W B C$ white blood cells, $C R P$ C-reactive protein, $P C T$ procalcitonin, $A S T$ aspartate-aminotransferase, $A L T$ alanine aminotransferase, $C P K$ creatine-phosphokinase, $L D H$ lactate dehydrogenase, $N A$ not available, +++ severe symptoms, + mild symptoms, - absence of symptoms 


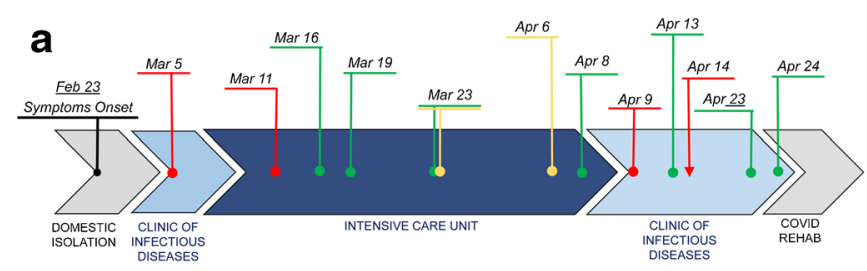

b
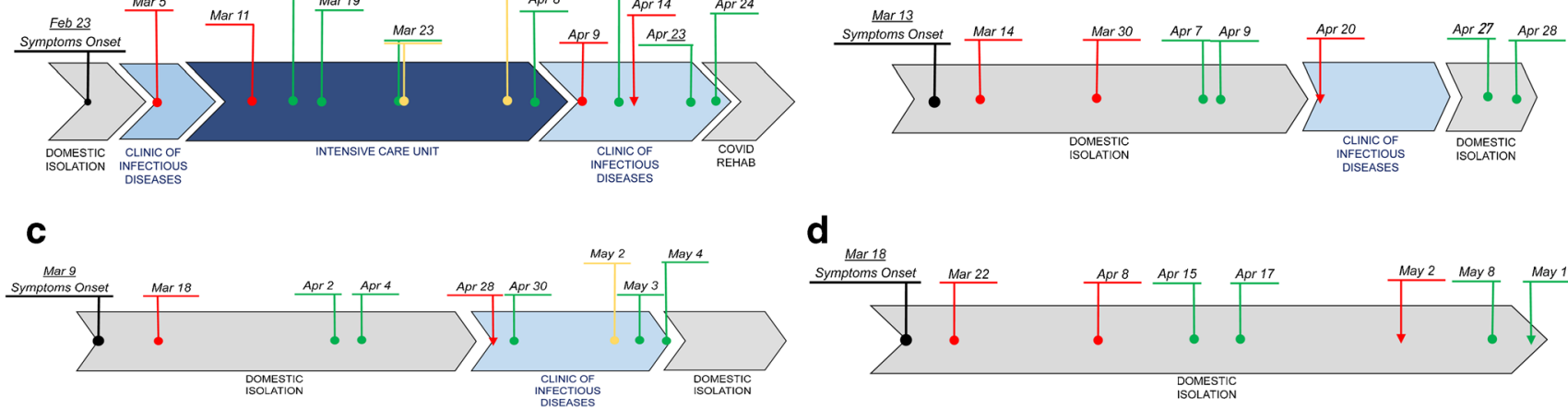

d
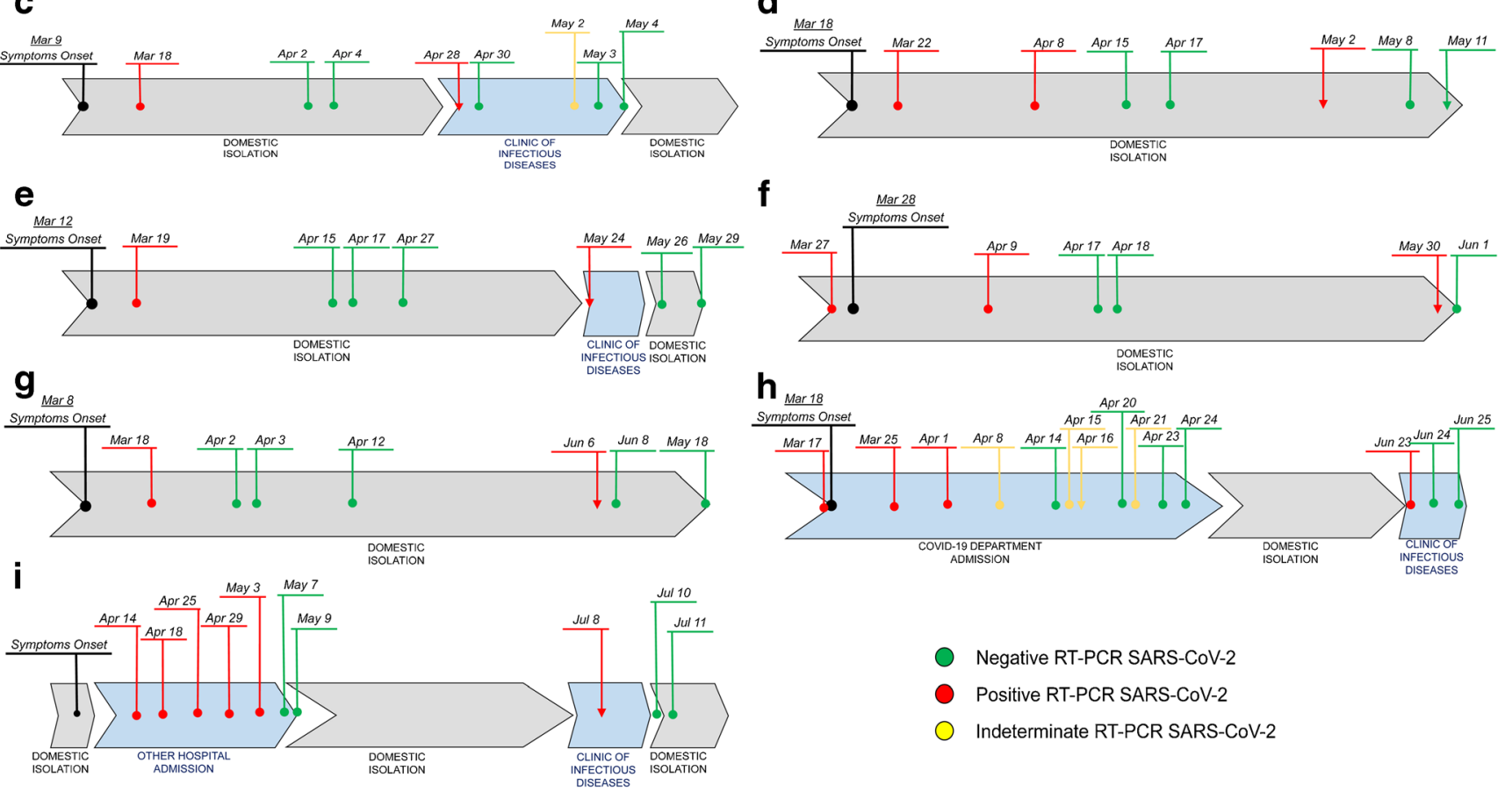

Fig. 1 Respiratory sample timeline of each described case. Above the timeline: time of onset of symptoms and collection of samples. Under the timeline: movement of patient (e.g., hospitalization, discharge, domestic isolation). Black: onset of symptoms. Red: positive sample for

severe acute respiratory syndrome (SARS-CoV-2). Green: negative sample for SARS-CoV-2. Yellow: indeterminate sample for SARSCoV-2. Point: exam performed with traditional RT-PCR. Arrow: exam performed with Xpert® Xpress SARS-CoV-2, Cepheid

conditions were good, and the criteria for discharge were met, the patient was transferred to a COVID-dedicated rehabilitative ward.

The swab sample collected on April 14 (resulted positive) was stored, and culture-based virus isolation in Vero E6 cells was performed as previously described to evaluate the potential infectivity of the clinical specimen [6]. No virus was isolated, and viral RNA on supernatant was not detected (Xpert ${ }^{\circledR}$ Xpress SARS-CoV-2, Cepheid).

\section{Case 2}

A 51-year-old man with a history of hypertension, tobacco use, and dyslipidemia developed fever until $38.3{ }^{\circ} \mathrm{C}$ with no other apparent symptoms on March 13, 2020. He underwent a nasopharyngeal swab which came positive for SARS-CoV-2 with RT-PCR (Allplex ${ }^{\text {TM }} 2019-\mathrm{nCoV}$ Assay). He was not hospitalized, as he did not complain of dyspnea and gradually became afebrile. He performed a follow-up nasopharyngeal swab, which came negative on April 7 (Allplex ${ }^{\mathrm{TM}}$ 2019-

nCoV Assay). Afterwards, he went to the hospital for persistent retrosternal sense of weight with efforts. He was hospitalized once he underwent a screening swab test $(\mathrm{Xpert} \circledast$ Xpress SARS-CoV-2, Cepheid) in the emergency room that tested positive on April 20. On April 21, his serology was compatible with a previous SARS-CoV-2 infection (IgG 23.6 AU/ $\mathrm{mL}$ ). He denied contact during quarantine with confirmed or possible COVID-19 cases.

In the following days, the pain disappeared, and his clinical features resulted normal. The patient was discharged in good clinical conditions with indication to repeat quarantine and swab tests that came negative for SARS-CoV-2 (Allplex ${ }^{\mathrm{TM}}$ 2019-nCoV Assay) on April 27 and 28 (Fig. 1b).

\section{Case 3}

A 45-year-old woman with a history of iatrogenic hypothyroidism developed fever until $38{ }^{\circ} \mathrm{C}$ with arthro-myalgia, cough, headache, and conjunctival hyperemia from March 9, 2020. She also complained of dyspnea and desaturation from 
March 16. She was not in contact with a known case of SARSCoV-2. She underwent a nasopharyngeal swab, which tested positive (Allplex ${ }^{\mathrm{TM}}$ 2019-nCoV Assay). She was not hospitalized. Fever and other symptoms disappeared after 2 weeks, while arthro-myalgia and headache persisted.

She performed two follow-up nasopharyngeal swabs on April 2 and 4, which tested negative (Allplex ${ }^{\mathrm{TM}}$ 2019-nCoV Assay) and a serologic test that was positive for $\operatorname{IgG}$ (SCREEN® TEST COVID-19, ScreenItalia).

While on quarantine, she referred a sense of chest weight and underwent computed tomography (CT) of the thorax that showed bilateral ground-glass opacities and interlobular septal thickening.

On April 28, she was hospitalized after a positive nasopharyngeal swab test; RNA gene " $N$ " of SARS-CoV-2 was detected with a $\mathrm{Ct}$ value of 43 (Xpert ${ }^{\circledR}$ Xpress SARS-CoV-2, Cepheid). At the same time, her SARS-CoV-2 serology was positive for IgG $102 \mathrm{AU} / \mathrm{mL}$.

During the hospitalization, pain progressively disappeared, and her clinical features resulted normal. No complications occurred. The patient was discharged in good clinical condition after two subsequent negative nasopharyngeal swabs (May 3 and 4, respectively; Allplex ${ }^{\mathrm{TM}}$ 2019-nCoV Assay) (Fig. 1c).

\section{Case 4}

A 74-year-old man with no history of previous diseases developed fever until $38^{\circ} \mathrm{C}$ with anosmia, dysgeusia, and lack of appetite on March 18, 2020. He denied dyspnea. His probable COVID-19 contact was his wife, so he underwent a nasopharyngeal swab, which came positive on March 22 (Allplex ${ }^{\mathrm{TM}}$ 2019-nCoV Assay). Considering his mild symptoms, he was not hospitalized.

He performed two follow-up pharyngeal swabs on April 15 and 17, which came negative (Allplex ${ }^{\mathrm{TM}}$ 2019-nCoV Assay). $\mathrm{He}$ also underwent a SARS-CoV-2 qualitative serologic test that was positive for IgG (SCREEN® TEST COVID-19, ScreenItalia).

During the following quarantine, he was always asymptomatic, but his CT of the chest showed bilateral interlobular septal thickening without interstitial pneumonia signs. Basing on this radiological sign, he underwent a nasopharyngeal swab test for SARS-CoV-2 that resulted positive on May 2 with detection of RNA genes " $E$ " and " $N$ " at Ct values of 32 and 35, respectively (Xpert ${ }^{\circledR}$ Xpress SARS-CoV-2, Cepheid).

The patient presented two subsequent negative nasopharyngeal swabs on May 8 and 11, both performed with RTPCR assay and Xpert ${ }^{\circledR}$ Xpress SARS-CoV-2 (Cepheid) (Fig. 1d). At the same time, his SARS-CoV-2 serology was positive for $\operatorname{IgG}(52.9 \mathrm{AU} / \mathrm{mL})$.

\section{Case 5}

A 42-year-old woman with no history of previous diseases developed cough, mild dyspnea, sore throat, anosmia, and dysgeusia on March 12, 2020. She denied fever. She underwent a nasopharyngeal swab that tested positive on March 19 (Allplex ${ }^{\mathrm{TM}}$ 2019-nCoV Assay). Considering her mild symptoms, she was not hospitalized. During the quarantine period, she was always afebrile while the other symptoms gradually improved and completely disappeared on April 14.

She performed two follow-up nasopharyngeal swabs on April 15 and 17, which came negative (Allplex ${ }^{\mathrm{TM}}$ 2019-nCoV Assay). She also underwent a SARS-CoV2 qualitative serologic test that was positive for $\operatorname{IgG}$ (SCREEN® TEST COVID-19, ScreenItalia).

On May 24, because of chest pain and arthro-myalgia, the patient was hospitalized. She underwent a nasopharyngeal swab test for SARS-CoV-2 that resulted positive with detection of genes " $E$ " and " $N$ " at $\mathrm{Ct}$ values of 44 and 37, respectively (Xpert ${ }^{\circledR}$ Xpress SARS-CoV-2, Cepheid). She was discharged $24 \mathrm{~h}$ later.

The patient presented two subsequent negative nasopharyngeal swabs on May 26 and 29, respectively (Allplex ${ }^{\mathrm{TM}}$ 2019-nCoV Assay) (Fig. 1e).

As in case 1, the swab sample of May 24 was cultured with Vero E6 cells. No viral replication was observed, and no viral RNA on the supernatant was detected.

\section{Case 6}

A 77-year-old woman with chronic respiratory disease and cardiomyopathy had presumably a close contact with a positive case. She underwent nasopharyngeal swab on March 27 that came positive (Allplex ${ }^{\mathrm{TM}}$ 2019-nCoV Assay). The day after, she started complaining of generalized arthro-myopathy but no respiratory symptoms. She was considered healed when her nasopharyngeal swabs for SARS-CoV-2 came negative (May 17 and 19, Allplex ${ }^{\text {TM }}$ 2019-nCoV Assay).

She tested positive in an ulterior test, performed on May 30 before a cardiological follow-up visit with detection of genes " $E$ " and " $N$ " at $\mathrm{Ct}$ values of 40 and 38 , respectively (nasopharyngeal swab; Xpert ${ }^{\circledR}$ Xpress SARS-CoV-2, Cepheid). The following swab was performed on June 1 and came negative (RT-PCR assay) (Fig. 1f). At the same time, SARS-CoV-2 serology was compatible with a previous infection (IgG $32.3 \mathrm{AU} / \mathrm{mL}$ ).

The sample of May 30 was inoculated onto Vero E6 cells, without any cytopathic effect development, and viral RNA on the supernatant was not found. 


\section{Case 7}

A 26-year-old physician working in a hospital in Northern Italy probably came in contact with a positive case during his professional activity. On March 8, 2020, he developed headache, arthro-myalgia, ageusia, anosmia, and dyspnea on exertion. He underwent a nasopharyngeal swab that tested positive on March 19 (RT-PCR assay). Considering his mild symptoms, he was not hospitalized. During the quarantine period, his clinical conditions were fine, but he kept on having mild cough and complaining of dyspnea.

He performed follow-up nasopharyngeal swabs on April 2, 3 , and 12, which came negative (RT-PCR assay), and a highresolution $\mathrm{CT}$ that showed two millimetric ground-glass opacities.

On May 5, 2020, he repeated the nasopharyngeal swab and serology test (method not available) that resulted negative.

On June 6, he was admitted to Perugia Hospital for a bone marrow donation and performed a new nasopharyngeal swab test for SARS-CoV-2 that resulted positive with detection of genes " $E$ " and " $N$ " at $\mathrm{Ct}$ values of 43 and 40 , respectively (Xpertß Xpress SARS-CoV-2, Cepheid).

The patient presented two subsequent negative pharyngeal swabs on June 8 and 10, respectively (RT-PCR assay) (Fig. $1 \mathrm{~g})$. His SARS-CoV-2 serology was positive for IgG (18.7 AU/mL).

The swab sample of June 6, 2020, was inoculated in Vero E6 cell culture. No virus was isolated, and no viral RNA on the supernatant was detected.

\section{Case 8}

A diabetic man, aged 50 years old, was hospitalized on March 18 for dyspnea after being diagnosed with COVID19 with a nasopharyngeal swab (Allplex ${ }^{\mathrm{TM}}$ 2019-nCoV Assay). During the hospitalization, his respiratory exchanges gradually worsened, needing noninvasive ventilation. Tocilizumab, wide-range antibiotic treatment, hydroxychloroquine, and corticosteroids were also administered. His infection was classified as overcome once he collected two negative nasopharyngeal swabs (Allplex ${ }^{\mathrm{TM}} 2019$ nCoV Assay) (Fig. 1h).

He underwent a follow-up CT scan that showed the ground-glass aspect of parenchyma and "crazy paving" phenomena in the inferior and superior right lobes. He was discharged on April 27.

The patient went to the hospital on June 23 for the persistence of headache, arthro-myalgias, asthenia, and insomnia. He was hospitalized again as a sample performed in the emergency room resulted positive (nasopharyngeal swab; Xpert ${ }^{\circledR}$ Xpress SARS-CoV-2, Cepheid). At the same time, SARS$\mathrm{CoV}-2$ serology showed $\mathrm{IgG}=170 \mathrm{AU} / \mathrm{mL}$. Subsequently, he was rapidly discharged after two negative pharyngeal swabs and negative SARS-CoV-2 culture in Vero E6 cells.

\section{Case 9}

A 77-year-old man with a history of cardiomyopathy, atrial fibrillation, diabetes mellitus type 2, alcoholic cirrhosis, myelodysplastic syndrome, and hepatic neoformation developed fever with no other apparent symptoms on April 10, 2020. He was hospitalized after performing a nasopharyngeal swab with RT-PCR assay, which came positive (Allplex ${ }^{\mathrm{TM}}$ 2019-nCoV Assay). As he became afebrile and his parameters were in range, he was discharged after a follow-up pharyngeal swab that came negative on May 7 (Allplex ${ }^{\mathrm{TM}}$ 2019-nCoV Assay).

During quarantine, he was asymptomatic. On July 8 , he went to the emergency room after seeing blood in his stools. He underwent a screening nasopharyngeal swab (Xpert ${ }^{\circledR}$ Xpress SARS-CoV-2, Cepheid) that tested positive with detection of genes " $E$ " and " $N$ " at Ct values of 33 and 35 , respectively. His serology was compatible with a previous infection with SARS-CoV-2 ( $\mathrm{IgG}=199.0 \mathrm{AU} / \mathrm{mL})$. He denied contact during quarantine with confirmed or possible COVID19 cases.

The patient was discharged in good clinical conditions after two further swab tests for SARS-CoV-2 (Allplex ${ }^{\mathrm{TM}}$ 2019nCoV Assay), which came negative on July 10 and 11 (Fig. 1i). The swab sample of June 6,2020 , was inoculated in VeroE6 cell culture. No virus was isolated, and no viral RNA on the supernatant was detected.

\section{Systematic review results}

A total of 82 papers matched the eligibility criteria [9-90]. No clinical or observational trials were found. Among those, there were 32 case reports and 50 case series. Furthermore, 5 review/minireview articles have been found [63, 64, 91-93]. Applying clinical criteria based on literature sources [94], we identified 1341 cases of COVID-19 that presented new positive respiratory samples after recovery. We analyzed data also including our nine presented cases, with a total of 1350 . The characteristics of the patients are summarized in Table 2.

Recurrence indistinctly occurred in the same rate in male and in female patients with a small predominance of female cases (male $43.8 \%$, number of patients, $N 1076$ ). The patients were admitted to the hospital in a mean of 6.1 days (standard deviation, SD, 7.6 days; $N$ 81) after symptoms onset. Only four patients were not hospitalized (cases 4, 5, 6, and 7). Recurrence was not associated with a specific age (mean age, 47.4 years old; SD, 19.3; range, $4-91$ years old; $N 160$ ) or comorbidity ( $34.5 \%$ of patients had at least one comorbidity, $N$ 287). 
Table 2 Demographics, comorbidities, clinical presentation, and timing of respiratory samples for severe acute respiratory syndrome-coronavirus2 (SARS-CoV-2) and outcome

\begin{tabular}{|c|c|}
\hline & $N 1350$ \\
\hline Sex (N 1076), male percentage $(\%)$ & 43.8 \\
\hline \multicolumn{2}{|l|}{ Age $(N 160)$} \\
\hline Mean, years (range) & $47.4(4-91)$ \\
\hline $\mathrm{SD}$, years & 19.3 \\
\hline \multicolumn{2}{|l|}{ Age (including case series, $N 780$ ) } \\
\hline Weighted arithmetic mean, years & 47.7 \\
\hline $\begin{array}{l}\text { Hospital admission, days after symptom onset ( } N 81) \text {, } \\
\text { mean (SD) }\end{array}$ & $6.1(7.6)$ \\
\hline Charlson comorbidity index ( $N$ 107), median [IQR] & $0[0-2]$ \\
\hline Presence of comorbidity $(N 287), \%$ & 34.5 \\
\hline
\end{tabular}

Symptoms at presentation

66.3

Cough $(N 317), \%$

Dyspnea $(N 254), \%$

Nausea/diarrhea (N 276), \% $\quad 8.3$

Arthro-myalgia (N 281), \% $\quad 12.8$

Peripheral WBC ( $N$ 27)

Mean, /mmc (range)

$\mathrm{SD}, / \mathrm{mmc}$

Lymphocytes ( $N 33)$

Mean, /mmc (range)

$\mathrm{SD}, / \mathrm{mmc}$

Neutrophils ( $N 22)$

Mean, /mmc (range)

$\mathrm{SD}, / \mathrm{mmc}$

$\mathrm{CRP}(N 32)$

Mean, mg/dL (range)

$\mathrm{SD}, \mathrm{mg} / \mathrm{dL}$

Pneumonia (N316), \%

ICU admission ( $N 232), \%$

Treatment (N 270), \%

First positive respiratory samples

Days from symptoms onset ( $N$ 120), mean (SD)

Fever (N 308), \%

Symptoms (N 284), \%

Type of samples ( $N$ 494)

Swabs, \%

Salivary tests, \%

Sputum, \%

Tracheal aspirate, $\%$

First negative respiratory samples

Days from symptoms onset ( $N$ 111), mean (SD)

Fever (N 1033), \%

Symptoms (N 324), \%

Type of samples ( $N$ 458)

Swabs, \%

Salivary tests, \%

Sputum, \%

Tracheal aspirate, $\%$

New positive respiratory samples

Days from symptoms onset ( $N$ 123), mean (SD)

Fever ( $N$ 805), \%

Symptoms ( $N 1195), \%$

Type of samples ( $N$ 821)

Swabs, \%

Salivary tests, \%

Sputum, \%

Tracheal aspirate, $\%$

SARS-CoV-2 IgG positivity ( $N$ 544), $\%$

New negative respiratory samples

Days from symptoms onset (N 76), mean (SD) 6281.5

2858.0

$1143.4(60-2948)$

636.4

4740.4

(1595.9-9648.0)

2858.0

$2.8(0.1-10.0)$

2.9

82.0

2.6

85.2

$6.2(4.7)$

68.8

87.7

98.8

0.4

0.8

0

$19.1(10.2)$

0.1

28.7

98.3

0.4

1.1

0.2

34.5 (18.7)

5.7

27.9

97.7

0.2

1.9

0.1

92.5

$41.2(21.5)$
Table 2 (continued)

\begin{tabular}{ll}
\hline & $N 1350$ \\
\hline Fever (N 113), \% & 0 \\
Symptoms (N 113), \% & 4.4 \\
Type of samples (N 100) & \\
Swabs, \% & 95.1 \\
Salivary tests, \% & 0.7 \\
Sputum, \% & 4.3 \\
Tracheal aspirate, \% & 0 \\
Outcome $(N$ 802) & \\
Recovery, \% & 91.6 \\
Improvement, \% & 5.1 \\
Still hospitalized, \% & 1.1 \\
Death, \% & 2.1 \\
\end{tabular}

Abbreviations: $N$ number of patients, STD standard deviation, IQR interquartile range, $W B C$ white blood cells, $C R P$ C-reactive protein, $I C U$ intensive care unit

The most common symptoms at infection onset included fever $(66.3 \%, N 320)$, cough $(52.3 \%, N 317)$, dyspnea $(19.3 \%$, $N 254)$, nausea or diarrhea $(8.3 \%, N 276)$, and arthro-myalgia $(12.8 \%, N 281)$.

As shown in Table 2, poor data are available about laboratory findings, but coherent to literature data concerning patients with SARS-CoV-2 infection [95]. Many cases also had CT scans or chest $\mathrm{x}$-rays of patients which revealed the typical radiological sign of SARS-CoV-2 lung involvement $(82.0 \%, N 316)$. Most patients underwent some antiviral treatment $(85.2 \%, N 260)$.

Only six patients (included case 1 of our case series) required ICU admission (2.6\%, N232). In particular, case 1 and 3 other cases have been in ICU before the presumptive reactivation of SARS-CoV-2 infection, and only two patients needed ICU admission at the second episode $[47,55]$.

The first positive respiratory sample was collected in mean after 6.2 days (SD 4.7, $N$ 120) from symptom onset. In that phase, $87.7 \%$ ( $N 284)$ of patients presented symptoms related to COVID-19, and $68.8 \%$ ( $N 308)$ of patients had fever.

In Table 2, we reported the first negative respiratory sample only if followed by a second negative sample. It occurred in mean after 19.1 days (SD 10.2 days, $N 120$ ). In this phase, $28.7 \%$ ( $N 324$ ) of patients presented persisting but improving symptoms. Only in one case $(0.1 \%, N 1033)$ did fever persist because of a Klebsiella pneumoniae bloodstream infection, documented at the same time.

These patients underwent follow-up respiratory sample collection after being declared recovered. New positive respiratory samples were found in mean 34.5 days (SD 18.7 days, $N 123$ ) after symptoms onset. Some patients presented fever $(5.6 \%, N 805)$ and/or were still symptomatic $(27.6 \%, N 1195)$. Most of them reported mild cough and respiratory symptoms. At that time, $92.5 \%$ of patients already had IgG against SARSCoV-2. 
Data concerning the following negative respiratory samples are available for 113 patients; none presented fever and $4 \%$ of the patients were mildly symptomatic.

The outcome was available for 802 patients. Among these, 91.6\% recovered, $5.0 \%$ improved, $1.1 \%$ were still hospitalized at the time of data collection, and $2.1 \%$ died.

\section{Discussion}

SARS-CoV-2 is a new coronavirus that since its discovery has been spreading all over the world, causing an impressive amount of deaths [96]. It is believed that patients infected with SARS-CoV-2 carry protective antibodies after recovery [97]. In literature, nonetheless, a series of cases of recurrences is reported, which means positivity for SARS-CoV-2 after two negative respiratory samples [98].

We need further data to determine risk factors, timing, and mechanisms that can cause it. Recurrence might probably be related to host factors (virologic status, underlying medical conditions, and therapy administered), characteristics of the virus itself, sample collection, and processing [98]. Currently, no reliable predictive marker of reactivation was found.

SARS-CoV-2 recurrence will be a vexing and persistent problem. Considering numerous patients infected or previously exposed to the virus, such a possibility poses a major public health burden [65].

The aim of the present study was to explore if the cases of suspected recurrence reported in the literature and in our clinic may be caused by a flawed sample or an incomplete clearance of the virus, or if effectively recovered people may be infected anew.

According to the presented data, the hypothesis of a recurrence seems to be improbable. Indeed, most of the patients were afebrile (5.7\% of patients had fever), and symptoms were mild. These data depose for slow viral clearance and disease resolution instead of reactivation. Almost $97 \%$ of patients subsequently improved or recovered. Among 1350 cases, four patients died after presumptive recurrence, but it is not clear if the episode could be due to recurrence of COVID-19 [26]. Interestingly, Lafaye et al. described a geriatric case (case 1) with probable COVID-19 recurrence as he had clinical and radiological worsening, absence of neutralizing antibody, and positive cell culture during the second episode [77].

A real case of re-infection was described by Wang To et al. In this case, epidemiological, clinical, serological (IgG seroconversion), and genomic analyses confirmed that the patient had re-infection by a different strain of SARS-CoV-2 [74].

Osman et al. performed a review of re-positive cases after discharge from hospitals in China. They concluded that the repositivization might be attributed to false-negative laboratory results and prolonged viral shedding, rather than re-infection [91]. However, the authors, in line with another review performed by Han et al., suggested that health authorities need to consider the importance of maintaining social distancing, even after the patients' recovery [91, 92].

Cento et al. retrospectively analyzed data of 2521 recovered COVID-19. Negative-to-positive RT-PCR fluctuations occurred in 264/2521 patients, while none of them has ever shown a recurring of COVID-19 symptoms, regardless of RTPCR results [82].

Kang et al. analyzed clinical and epidemiological information of 292 re-positive cases from the South Korea Centers for Disease Control and Prevention (KCDC). Patients were asymptomatic or complained about minor symptoms. The authors suggested that RNA of the "dead virus" remaining in the recovered patient's body is amplified during the RT-PCR process. Furthermore, as SARS-CoV-2 does not cause chronic infection (seen as a latent stage), its reactivation is not virologically possible. They also concluded that comprehending the above evidence, re-positive cases are not contagious [42].

Concerning our nine cases, none presented severe disease or complications at the time of presumed recurrence. All tested patients $(N 8)$ had antibody against the $\mathrm{S} 1$ and $\mathrm{S} 2$ subunit of SARS-CoV-2 spike protein with sufficient titer immediately before or during the presumptive recurrence. These data are in contrast with the hypothesis of recurrence of COVID-19.

Another important issue was to establish if these patients could be contagious again. To this purpose, 6 swab samples of the supposed "recurrence" in our patient cohort were stored, and the cultivability of SARS-CoV-2 in Vero E6 cells was assessed as previously described [6]. In all these cases, after $72 \mathrm{~h}$ of culture on Vero E6 cells, no virus replication has been observed, and viral RNA on supernatant was not detected. Since the first SARS-CoV-2 virus was isolated by our virology laboratory, many other swab samples have been cultured to isolate as much different virus strains as possible. We found that symptomatic patients with positive RT-PCR tests with $\mathrm{Ct}$ values $<25$ easily provided cultivable SARS-CoV-2 viruses from their specimens. As previously reported, the results of RT-PCR from swab samples of re-positive patients of our cohort always showed $\mathrm{Ct}$ values above 24 , so the uncultivability of these samples should be considered easily predictable [99]. This also strengthens the hypothesis of a "dead virus" that remained in the recovered respiratory tracts instead of a recurrence of infection. Furthermore, our results confirmed what previously declared by KCDC that tested negative viral cell culture of 108 re-positive cases [42].

Although these data should be confirmed in a larger number of cases, they strongly suggest that patients previously considered recovered and with a subsequent new sample positive for SARS-CoV-2 should not be considered contagious.

Limits of our study are the small number of cases; the incompleteness of some literature data, such as the detailed 
description of criteria for positivity and negativity; and the heterogeneity of the entire study cohort. Strengths are the analysis of all available literature about the recurrence of COVID-19 and the univocal answers to the issues.

\section{Conclusions}

In conclusion, our results suggest that in most cases the presumptive recurrence is indeed a prolonged, not contagious, viral RNA persistence in the respiratory tract, probably due to a slow disease resolution. Further studies are necessary to definitively understand if a COVID-19 recurrence is possible and whether it could be considered as a real threat.

Code availability Available on reasonable request.

Author contributions Daniela Francisci, Anna Gidari, Marco Nofri, and Luca Saccarelli contributed to the study conception and design. Material preparation and data collection and analysis were performed by Anna Gidari and Marco Nofri. The first draft of the manuscript was written by Anna Gidari, Marco Nofri, and Luca Saccarelli, and all authors commented on previous versions of the manuscript. All authors read and approved the final manuscript.

Funding Open access funding provided by Università degli Studi di Perugia within the CRUI-CARE Agreement.

Data availability Available on reasonable request.

\section{Compliance with ethical standards}

Conflict of interest The authors declare that they have no competing interests.

Open Access This article is licensed under a Creative Commons Attribution 4.0 International License, which permits use, sharing, adaptation, distribution and reproduction in any medium or format, as long as you give appropriate credit to the original author(s) and the source, provide a link to the Creative Commons licence, and indicate if changes were made. The images or other third party material in this article are included in the article's Creative Commons licence, unless indicated otherwise in a credit line to the material. If material is not included in the article's Creative Commons licence and your intended use is not permitted by statutory regulation or exceeds the permitted use, you will need to obtain permission directly from the copyright holder. To view a copy of this licence, visit http://creativecommons.org/licenses/by/4.0/.

\section{References}

1. World Health Organization (2020) WHO Director-General's opening remarks at the media briefing on COVID-19. Gen Open. remarks media Brief. COVID-19. https://www.who.int/dg/speeches/ detail/who-director-general-s-opening-remarks-at-the-mediabriefing-on-covid-19\%2D\%2D-11-march-2020
2. Pal M, Berhanu G, Desalegn C, Kandi V (2020) Severe acute respiratory syndrome coronavirus-2 (SARS-CoV-2): an update. Cureus. https://doi.org/10.7759/cureus.7423

3. World Health Organization (2020) WHO coronavirus disease (COVID-19) dashboard. World Health Organ https://covid19. who.int/?gclid=CjwKCAjwx9 4BRAHEiwApAt0zv9 oRgc4Y31g9Mmx4jJ56WBZ8jwC 1 NhTcUar5dVc58mih0NG T3VRoC_XEQAvD_BwE

4. World Health Organization (2020) Criteria for releasing COVID-19 patients from isolation. Criteria Releas. COVID-19 patients from Isol. https://www.who.int/publications/i/item/criteria-for-releasingcovid-19-patients-from-isolation

5. European Centre for Disease Prevention and Control. Diagnostic testing and screening for SARS-CoV-2. https://www.ecdc.europa. eu/en/covid-19/latest-evidence/diagnostic-testing

6. Keyaerts E, Vijgen L, Maes P, Neyts J, Van Ranst M (2005) Growth kinetics of SARS-coronavirus in Vero E6 cells. Biochem Biophys Res Commun. https://doi.org/10.1016/j.bbrc.2005.02.085

7. Kim J-M, Kim HM, Lee EJ, Jo HJ, Yoon Y, Lee N-J et al (2020) Detection and isolation of SARS-CoV-2 in serum, urine, and stool specimens of COVID-19 patients from the Republic of Korea. Osong Public Heal Res Perspect. https://doi.org/10.24171/j.phrp. 2020.11.3.02

8. Moher D, Shamseer L, Clarke M, Ghersi D, Liberati A, Petticrew $M$ et al (2016) Preferred reporting items for systematic review and meta-analysis protocols (PRISMA-P) 2015 statement. Rev Esp Nutr Hum Diet. https://doi.org/10.1186/2046-4053-4-1

9. Li Y, Hu Y, Yu Y, Zhang X, Li B, Wu J et al (2020) Positive result of Sars-Cov-2 in faeces and sputum from discharged patient with COVID-19 in Yiwu, China. J Med Virol. https://doi.org/10.1002/ jmv. 25905

10. Yuan B, Liu H-Q, Yang Z-R, Chen Y-X, Liu Z-Y, Zhang K, Cheng W, Li W-X, An Y-W, Wang J-C, Song S Recurrence of positive SARS-CoV-2 viral RNA in recovered COVID-19 patients during medical isolation observation. Res Sq https:/www.researchsquare. com/article/rs-22829/v1

11. Tao J, Hu Z, Liu J, Pang P, Fu G, Qian A, Chen S, Lin L, Cao G, Sun H, YWM Y (2020) Positive RT-PCR test results in discharged COVID-19 patients: reinfection or residual. Res Sq. https://doi.org/ 10.21203/rs.3.rs-18042/v1

12. Nicastri E, D'Abramo A, Faggioni G, De Santis R, Mariano A, Lepore L et al (2020) Coronavirus disease (COVID-19) in a paucisymptomatic patient: Epidemiological and clinical challenge in settings with limited community transmission, Italy, February 2020. Eurosurveillance. https://doi.org/10.2807/1560-7917.ES. 2020.25.11.2000230

13. Peng J, Wang M, Zhang G, Lu E (2020) Seven discharged patients turning positive again for SARS-CoV-2 on quantitative RT-PCR. Am J Infect Control. https://doi.org/10.1016/j.ajic.2020.03.017

14. Dou P, Zhang S, Wang C, Cai L, Liu Z, Xu Q et al (2020) Serial CT features in discharged COVID-19 patients with positive RT-PCR re-test. Eur J Radiol. https://doi.org/10.1016/j.ejrad.2020.109010

15. Zheng KI, Wang XB, Jin XH, Liu WY, Gao F, Chen YP et al (2020) A case series of recurrent viral RNA positivity in recovered COVID-19 Chinese patients. J Gen Intern Med. https://doi.org/10. 1007/s11606-020-05822-1

16. Wang X, Xu H, Jiang H, Wang L, Lu C, Wei X et al (2020) The clinical features and outcomes of discharged coronavirus disease 2019 patients: a prospective cohort study. QJM An Int J Med. https://doi.org/10.1093/qjmed/hcaa178

17. Bongiovanni M, Basile F (2020) Re-infection by COVID-19: a real threat for the future management of pandemia? Infect Dis (Auckl). https://doi.org/10.1080/23744235.2020.1769177

18. Fu W, Chen Q, Wang T (2020) Letter to the Editor: Three cases of re-detectable positive SARS-CoV-2 RNA in recovered COVID-19 
patients with antibodies. J Med Virol. https://doi.org/10.1002/jmv. 25968

19. Azzi L, Carcano G, Dalla Gasperina D, Sessa F, Maurino V, Baj A (2020) Two cases of COVID-19 with positive salivary and negative pharyngeal or respiratory swabs at hospital discharge: a rising concern. Oral Dis. https://doi.org/10.1111/odi.13368

20. Yang JR, Deng DT, Wu N, Yang B, Li HJ, Pan X Ben. Persistent viral RNA positivity during recovery period of a patient with SARS-CoV-2 infection. J Med Virol. 2020; doi: https://doi.org/10. $1002 / j m v .25940$

21. Jiang M, Li Y, Han M, Wang Z, Zhang Y, Du X (2020) Recurrent PCR positivity after hospital discharge of people with coronavirus disease 2019 (COVID-19). J Inf Secur. https://doi.org/10.1016/j. jinf.2020.03.024

22. Wang H, Li Y, Wang F, Du H, Lu X (2020) Rehospitalization of a recovered coronavirus disease 19 (COVID-19) child with positive nucleic acid detection. Pediatr Infect Dis J 39:e69. https://doi.org/ 10.1097/INF.0000000000002690

23. Cao H, Ruan L, Liu J, Liao W (2020) The clinical characteristic of eight patients of COVID-19 with positive RT-PCR test after discharge. J Med Virol. https://doi.org/10.1002/jmv.26017

24. Yoo SY, Lee Y, Lee GH, Kim DH (2020) Reactivation of SARSCoV-2 after recovery. Pediatr Int. https://doi.org/10.1111/ped. 14312

25. Loconsole D, Passerini F, Palmieri VO, Centrone F, Sallustio A, Pugliese S et al (2020) Recurrence of COVID-19 after recovery: a case report from Italy. Infection. https://doi.org/10.1007/s15010020-01444-1

26. Ravioli S, Ochsner H, Lindner G (2020) Reactivation of COVID19 pneumonia: a report of two cases. J Inf Secur. https://doi.org/10. 1016/j.jinf.2020.05.008

27. Lan L, Xu D, Ye G, Xia C, Wang S, Li Y et al (2020) Positive RTPCR test results in patients recovered from COVID-19. JAMA J Am Med Assoc. https://doi.org/10.1001/jama.2020.2783

28. Liu T, Wu S, Zeng G, Zhou F, Li Y, Guo F et al (2020) Recurrent positive SARS-CoV-2: immune certificate may not be valid. J Med Virol. https://doi.org/10.1002/jmv.26074

29. Chen M, An W, Xia F, Yang P, Li K, Zhou Q, Fang S, Liao Y, Xu X, Liu J, Liu S, Qin T, Zhang J, Wei W, Zhang Y, Guowei Zhang MZ (2020) Clinical characteristics of rehospitalized patients with COVID-19 in China. J Med Virol. https://doi.org/10.1002/jmv. 26002

30. Li J, Long X, Fang X, Zhang Q, Hu S, Lin Z et al (2020) SARSCoV-2 positivity in a discharged COVID-19 patient: a case report. Clin Microbiol Infect. https://doi.org/10.1016/j.cmi.2020.04.032

31. Zhao W, Wang Y, Tang Y, Zhao W, Fan Y, Liu G et al (2020) Characteristics of children with reactivation of SARS-CoV-2 infection after hospital discharge. Clin Pediatr (Phila). https://doi.org/10. 1177/0009922820928057

32. Feng ZJ, Yan K, Hua YH, Lin J, Jun ZJ, Cai T (2020) SARS-CoV2 turned positive in a discharged patient with COVID-19 arouses concern regarding the present standards for discharge. Int J Infect Dis. https://doi.org/10.1016/j.ijid.2020.03.007

33. Zhang B, Liu S, Dong Y, Zhang L, Zhong Q, Zou Y et al (2020) Positive rectal swabs in young patients recovered from coronavirus disease 2019 (COVID-19). J Inf Secur. https://doi.org/10.1016/j. jinf.2020.04.023

34. Zhu H, Fu L, Jin Y, Shao J, Zhang S, Zheng N et al (2020) Clinical features of COVID-19 convalescent patients with re-positive nucleic acid detection. J Clin Lab Anal. https://doi.org/10.1002/ jcla.23392

35. Zou Y, Wang B-R, Sun L, Xu S, Kong Y-G, Shen L-J et al (2020) The issue of recurrently positive patients who recovered from COVID-19 according to the current discharge criteria: investigation of patients from multiple medical institutions in Wuhan, China. J Infect Dis. https://doi.org/10.1093/infdis/jiaa301
36. Landi F, Gremese E, Rota E, Carfi A, Benvenuto F, Ciciarello F et al (2020) Positive RT-PCR nasopharyngeal swab in patients recovered from COVID-19 disease: when does quarantine really end? J Inf Secur. https://doi.org/10.1016/j.jinf.2020.08.034

37. An J, Liao X, Xiao T, Shen Q, Yuan J, Ye H, Qi F, Shen C, Yang L, Wang L, Cheng X, Li N, Cai Q, Wang F, Chen J, Liu Y, Wang Y, Zhang F, Yang F, Tan X, Lei Liu ZZ (2020) Clinical characteristics of the recovered COVID-19 patients with re-detectable positive RNA test. medrxiv. https://doi.org/10.1101/2020.03.26.20044222

38. Lu J, Peng J, Xiong Q, Liu Z, Lin H, Tan X et al (2020) Clinical, immunological and virological characterization of COVID-19 patients that test re-positive for SARS-CoV-2 by RT-PCR. EBioMedicine. https://doi.org/10.1016/j.ebiom.2020.102960

39. Ye H, Zhao C, Yang L, Yu W, Leng Z, Sun Y et al (2020) Twelve out of 117 recovered COVID-19 patients retest positive in a singlecenter study of China. EClinicalMedicine. https://doi.org/10.1016/j. eclinm.2020.100492

40. Wei DH, Nian CJ, Bin PX, Ling CX, Yixian-Zhang, Fang FS et al (2020) Prevalence and outcomes of re-positive nucleic acid tests in discharged COVID-19 patients. Eur J Clin Microbiol Infect Dis. https://doi.org/10.1007/s10096-020-04024-1

41. Wang L-F, Yan H, Zhang D, Yun Y, Zhang C, An C et al (2020) Clinical characteristics and imaging findings of 35 patients recovered from COVID-19 with recurrent positive RT-PCR test results. SSRN Electron J. https://doi.org/10.2139/ssrn.3564400

42. Korea Centers for Disease Control and Prevention. Findings from investigation and analysis of re-positive cases. 2020;doi: https:// www.cdc.go.kr/board/board.es? $\mathrm{mid}=\&$ bid= 0030

43. Xing Y, Mo P, Xiao Y, Zhao O, Zhang Y, Wang F (2020) Postdischarge surveillance and positive virus detection in two medical staff recovered from coronavirus disease 2019 (COVID-19), China, January to February 2020. Eurosurveillance. https://doi.org/10. 2807/1560-7917.ES.2020.25.10.2000191

44. Zheng J, Chen F, Han S, Zhou R, Li F, Liu H et al (2020) Recovery of pneumonia in 27 discharged COVID-19 patients with positive virus detection. Quant Imaging Med Surg 10. https://doi.org/10. 21037/QIMS-20-656

45. Li W, Su YY, Zhi SS, Huang J, Zhuang CL, Bai WZ et al (2020) Virus shedding dynamics in asymptomatic and mildly symptomatic patients infected with SARS-CoV-2. Clin Microbiol Infect. https:// doi.org/10.1016/j.cmi.2020.07.008

46. Mei Q, Li J, Du R, Yuan X, Li M, Li J (2020) Assessment of patients who tested positive for COVID-19 after recovery. Lancet Infect Dis. https://doi.org/10.1016/S1473-3099(20)30433-3

47. Duggan NM, Ludy SM, Shannon BC, Reisner AT, Wilcox SR (2020) Is novel coronavirus 2019 reinfection possible? Interpreting dynamic SARS-CoV-2 test results through a case report. Am J Emerg Med. https://doi.org/10.1016/j.ajem.2020.06.079

48. Chen C, Gao G, Xu Y, Pu L, Wang Q, Wang L et al (2020) SARSCoV-2-positive sputum and feces after conversion of pharyngeal samples in patients with COVID-19. Ann Intern Med. https://doi. org/10.7326/M20-0991

49. Bentivegna E, Sentimentale A, Luciani M, Speranza ML, Guerritore L, Martelletti P (2020) New IgM seroconversion and positive RT-PCR test after exposure to the virus in recovered COVID-19 patient. J Med Virol. https://doi.org/10.1002/jmv. 26160

50. Wang G, Yu N, Xiao W, Zhao C, Wang Z (2020) Consecutive false-negative rRT-PCR test results for SARS-CoV-2 in patients after clinical recovery from COVID-19. J Med Virol. https://doi. org/10.1002/jmv.26192

51. Alfano G, Perrone R, Fontana F, Mori G, Lucchi L, Guaraldi G et al (2020) Long-term effects of COVID-19 in a patient on maintenance dialysis. Hemodial Int. https://doi.org/10.1111/hdi.12859

52. Györfi AH, Kopp M, May M, Vetter M, Uder M, Kremer AE et al (2020) Glucocorticoid-induced relapse of COVID-19 in a patient 
with sarcoidosis. Ann Rheum Dis. https://doi.org/10.1136/ annrheumdis-2020-218258

53. Chen Y, Bai W, Liu B, Huang J, Laurent I, Chen F et al (2020) Reevaluation of retested nucleic acid-positive cases in recovered COVID-19 patients: Report from a designated transfer hospital in Chongqing, China. J Infect Public Health. https://doi.org/10.1016/j. jiph.2020.06.008

54. Chen D, Xu W, Lei Z, Huang Z, Liu J, Gao Z et al (2020) Recurrence of positive SARS-CoV-2 RNA in COVID-19: a case report. Int J Infect Dis. https://doi.org/10.1016/j.ijid.2020.03.003

55. Gousseff M, Penot P, Gallay L, Batisse D, Benech N, Bouiller K et al (2020) Clinical recurrences of COVID-19 symptoms after recovery: viral relapse, reinfection or inflammatory rebound? J Inf Secur. https://doi.org/10.1016/j.jinf.2020.06.073

56. Liu F, Bin CZ, Huang JS, Yu WY, Niu HY, Zhang Y et al (2020) Positive SARS-CoV-2 RNA recurs repeatedly in a case recovered from COVID-19: dynamic results from 108 days of follow-up. Pathog Dis. https://doi.org/10.1093/femspd/ftaa031

57. Wang J, Hang X, Wei B, Li D, Chen F, Liu W et al (2020) Persistent SARS-COV-2 RNA positivity in a patient for 92 days after disease onset: a case report. Medicine (Baltimore). https://doi. org/10.1097/MD.0000000000021865

58. Chae KJ, Jin GY, Lee CS, Lee HB, Lee JH, Kwon KS (2020) Positive conversion of COVID-19 after two consecutive negative RT-PCR results: a role of low-dose CT. Eur J Radiol. https://doi. org/10.1016/j.ejrad.2020.109122

59. Wang P (2020) Recurrent presence of SARS-CoV-2 RNA in a 33year-old man. J Med Virol. https://doi.org/10.1002/jmv.26334

60. Qiao XM, Xu XF, Zi H, Liu GX, Li BH, Du X et al (2020) Repositive cases of nucleic acid tests in discharged patients with COVID-19: a follow-up study. Front Med. https://doi.org/10. 3389/fmed.2020.00349

61. Luo A (2020) Positive SARS-Cov-2 test in a woman with COVID19 at 22 days after hospital discharge: a case report. J Tradit Chinese Med Sci. https://doi.org/10.1016/j.jtcms.2020.04.001

62. Ye X, Xiao X, Li B, Zhu W, Li Y, Wu J et al (2020) Low humoral immune response and ineffective clearance of SARS-Cov-2 in a COVID-19 patient with CLL during a 69-day follow-up. Front Oncol. https://doi.org/10.3389/fonc.2020.01272

63. Geling T, Huaizheng G, Ying C, Hua H (2020) Recurrent positive nucleic acid detection in a recovered COVID-19 patient: a case report and literature review. Respir Med Case Reps. https://doi. org/10.1016/j.rmcr.2020.101152

64. He F, Luo Q, Lei M, Fan L, Shao X, Hu K et al (2020) Successful recovery of recurrence of positive SARS-CoV-2 RNA in COVID19 patient with systemic lupus erythematosus: a case report and review. Clin Rheumatol. https://doi.org/10.1007/s10067-02005230-0

65. Ye G, Pan Z, Pan Y, Deng Q, Chen L, Li J et al (2020) Clinical characteristics of severe acute respiratory syndrome coronavirus 2 reactivation. J Inf Secur. https://doi.org/10.1016/j.jinf.2020.03.001

66. Gao G, Zhu Z, Fan L, Ye S, Huang Z, Shi Q et al (2020) Absent immune response to SARS-CoV-2 in a 3-month recurrence of coronavirus disease 2019 (COVID-19) case. Infection. https://doi.org/ 10.1007/s15010-020-01485-6

67. Alonso FOM, Sabino BD, Guimarães MAAM, Varella RB (2020) Recurrence of SARS-CoV-2 infection with a more severe case after mild COVID-19, reversion of RT-qPCR for positive and late antibody response: case report. J Med Virol. https://doi.org/10.1002/ jmv.26432

68. Liu F, Bin CZ, Song HJ, Ying NH, Yan YW, Zhang Y et al (2020) Repeated COVID-19 relapse during post-discharge surveillance with viral shedding lasting for 67 days in a recovered patient infected with SARS-CoV-2. J Microbiol Immunol Infect. https://doi.org/ 10.1016/j.jmii.2020.07.017
69. Mardani M, Nadji SA, Sarhangipor KA, Sharifi-Razavi A, Baziboroun M (2020) COVID-19 infection recurrence presenting with meningoencephalitis. New Microbes New Infect. https://doi. org/10.1016/j.nmni.2020.100732

70. Abdullah MS, Chong PL, Asli R, Momin RN, Mani BI, Metussin D et al (2020) Post discharge positive re-tests in COVID-19: common but clinically non-significant. Infect Dis (Auckl). https://doi.org/10. 1080/23744235.2020.1780309

71. Huang L, Deng H, Xia L, Zhou X (2020) Progressive CT findings and positive RT-PCR again of recovered and discharged patients with COVID-19. J Thorac Dis. https://doi.org/10.21037/jtd-201417

72. Zheng H, Tan J, Ma K, Meng W (2020) Changes in RT-PCR test results and symptoms during the menstrual cycle of female individuals infected with SARS-CoV-2: report of two cases. J Med Virol. https://doi.org/10.1002/jmv.26275

73. Jiazhen Zheng, Rui Zhou, Fengjuan Chen GT, Wu K, Li F, Liu H, $\mathrm{Lu} \mathrm{J}$, ZhouI J, et al. Incidence, clinical course and risk factor for recurrent PCR positivity in discharged COVID-19 patients in Guangzhou, China: a prospective cohort study. PLoS Negl. Trop. Dis. 2020;

74. To KK-W, Hung IF-N, Ip JD, Chu AW-H, Chan W-M, Tam AR et al (2020) COVID-19 re-infection by a phylogenetically distinct SARS-coronavirus-2 strain confirmed by whole genome sequencing. Clin Infect Dis. https://doi.org/10.1093/cid/ciaa1275

75. Tian M, Long Y, Hong Y, Zhang X, Zha Y (2020) The treatment and follow-up of 'recurrence' with discharged COVID-19 patients: data from Guizhou, China. Environ Microbiol. https://doi.org/10. 1111/1462-2920.15156

76. Cao S, Wu A, Li J, Li Y, Xia MWJ (2020) Recurrent recurrence of positive SARS-CoV-2 RNA in a COVID-19 patient. Res Sq (April 15). https://doi.org/10.21203/rs.3.rs-23197/v1

77. Lafaie L, Célarier T, Goethals L, Pozzetto B, Grange S, Ojardias E et al (2020) Recurrence or relapse of COVID-19 in older patients: a description of three cases. J Am Geriatr Soc. https://doi.org/10. 1111 /jgs. 16728

78. Zhou X, Zhou J, Zhao J (2020) Recurrent pneumonia in a patient with new coronavirus infection after discharge from hospital for insufficient antibody production: a case report. BMC Infect Dis. https://doi.org/10.1186/s12879-020-05231-z

79. Dou C, Xie X, Peng Z, Tang H, Jiang Z, Zhong Z et al (2020) A case presentation for positive SARS-CoV-2 RNA recurrence in a patient with a history of type 2 diabetes that had recovered from severe COVID-19. Diabetes Res Clin Pract. https://doi.org/10. 1016/j.diabres.2020.108300

80. Li J, Wei X, Tian W, Zou J, Wang Y, Xue W et al (2020) Clinical features of discharged COVID-19 patients with an extended SARSCoV-2 RNA positive signal in respiratory samples. Virus Res. https://doi.org/10.1016/j.virusres.2020.198047

81. Bongiovanni M, Vignati M, Giuliani G, Manes G, Arienti S, Pelucchi L et al (2020) The dilemma of COVID-19 recurrence after clinical recovery. J Inf Secur. https://doi.org/10.1016/j.jinf.2020. 08.019

82. Cento V, Colagrossi L, Nava A, Lamberti A, Senatore S, Travi G et al (2020) Persistent positivity and fluctuations of SARS-CoV-2 RNA in clinically-recovered COVID-19 patients. J Clean Prod. https://doi.org/10.1016/j.jinf.2020.06.024

83. Wong J, Koh WC, Momin RN, Alikhan MF, Fadillah N, Naing L (2020) Probable causes and risk factors for positive SARS-CoV-2 test in recovered patients: evidence from Brunei Darussalam. J Med Virol. https://doi.org/10.1002/jmv.26199

84. Liu BM, Yang QQ, Zhao LY, Xie W, Si XY (2020) Epidemiological characteristics of COVID-19 patients in convalescence period. Epidemiol Infect. https://doi.org/10.1017/ S0950268820001181 
85. Li C, Luo F, Xie L, Gao Y, Zhang N, Wu B. Chest CT study of fifteen COVID-19 patients with positive RT-PCR retest results after discharge. Quant Imaging Med Surg. 2020; doi: https://doi.org/10. 21037/QIMS-20-530

86. Habibzadeh P, Sajadi MM, Emami A, Karimi MH, Yadollahie M, Kucheki M et al (2020) Rate of re-positive RT-PCR test among patients recovered from COVID-19. Biochem Medica. https://doi. org/10.11613/BM.2020.030401

87. Wu F, Zhang W, Zhang L, Wang D, Wan Y (2020) Discontinuation of antiviral drugs may be the reason for recovered COVID-19 patients testing positive again. Br J Hosp Med. https://doi.org/10. 12968/hmed.2020.0156

88. Liu J, Lian R, Zhang G, Hou B, Wang C, Dong J et al (2020) Changes in serum virus-specific IgM/IgG antibody in asymptomatic and discharged patients with reoccurring positive COVID-19 nucleic acid test (RPNAT). Ann Med. https://doi.org/10.1080/ 07853890.2020 .1811887

89. Liu C, Ye L, Xia R, Zheng X, Yuan C, Wang Z et al (2020) Chest $\mathrm{CT}$ and clinical follow-up of discharged patients with COVID-19 in Wenzhou City, Zhejiang, China. Ann Am Thorac Soc. https://doi. org/10.1513/annalsats.202004-324oc

90. Gao Y, Shi C, Chen Y, Shi P, Liu J, Xiao Y, et al. A cluster of the Corona Virus Disease 2019 caused by incubation period transmission in Wuxi, China. J. Infect. 2020; doi: https://doi.org/10.1016/j. jinf.2020.03.042

91. Osman AA, Al Daajani MM, Alsahafi AJ (2020) Re-positive coronavirus disease 2019 PCR test: could it be a reinfection? New Microbes New Infect. https://doi.org/10.1016/j.nmni.2020.100748

92. Han Z, Battaglia F, Terlecky S (2020) Discharged COVID-19 patients testing positive again for SARS-CoV-2 RNA: a minireview of published studies from China. J Med Virol. https://doi.org/10. $1002 /$ jmv. 26250
93. Ulhaq ZS, Soraya GV, Fauziah FA (2020) Recurrent positive SARS-CoV-2 RNA tests in recovered and discharged patients. Rev Clin Esp. https://doi.org/10.1016/j.rce.2020.06.012

94. World Health Organization. WHO clinical management of severe acute respiratory infection (SARI) when COVID-19 disease is suspected. Who 2020;

95. Terpos E, Ntanasis-Stathopoulos I, Elalamy I, Kastritis E, Sergentanis TN, Politou M et al (2020) Hematological findings and complications of COVID-19. Am J Hematol. https://doi.org/ 10.1002/ajh.25829

96. Zheng J (2020) SARS-CoV-2: an emerging coronavirus that causes a global threat. Int J Biol Sci. https://doi.org/10.7150/ijbs.45053

97. Bao L, Deng W, Gao H, Xiao C, Liu J, Xue J et al (2020) Lack of reinfection in rhesus macaques infected with SARS-CoV-2. bioRxiv. https://doi.org/10.1101/2020.03.13.990226

98. Dominique Batisse, Nicolas Benech, Elisabeth Botelho-Nevers, Kevin Bouiller, Rocco Collarino, Anne Conrad, Laure Gallay, Francois Goehringer, Marie Gousseff, Dr Cédric Joseph, Adrien Lemaignen, Françoisxavier Lescure, Bruno Levy, Matthieu Mahevas, Paulin and BW. Clinical recurrences of COVID-19 symptoms after recovery: viral relapse, reinfection or inflammatory rebound? J Inf Secur. 2020;June 28. doi: https://doi.org/10.1016/j. jinf.2020.06.073

99. Bullard J, Dust K, Funk D, Strong JE, Alexander D, Garnett L et al (2020) Predicting infectious SARS-CoV-2 from diagnostic samples. Clin Infect Dis. https://doi.org/10.1093/cid/ciaa638

Publisher's note Springer Nature remains neutral with regard to jurisdictional claims in published maps and institutional affiliations. 